\title{
Algebra Teaching Knowledge of Professional and Non-professional Basic School Mathematics Teachers
}

\author{
Williams Osei*, Maud Kabukie Kubi*** \\ * Department of Mathematics and ICT Education, University of Cape Coast, Ghana \\ ** Department of Basic Education, University of Education, Winneba, Ghana \\ DOI: 10.29322/IJSRP.12.01.2022.p12107 \\ http://dx.doi.org/10.29322/IJSRP.12.01.2022.p12107
}

\begin{abstract}
Teachers' algebra teaching knowledge affect pupils' algebra knowledge, hence their general performance in mathematics. In view of this, the algebra teaching knowledge of basic school mathematics teachers should be monitored to positively affect pupils' mathematics performance. The study employed the Knowledge of Algebra for Teaching (KAT) framework to bring to light professional and non-professional basic school mathematics teachers' School Algebra Knowledge, Advanced Algebra Knowledge and Algebra Teaching knowledge as hypothesized as algebra knowledge types within the KAT framework. It finally looked at the improvement in the overall algebra teaching knowledge of basic school mathematics teachers as their years of teaching experience increase. The study employed descriptive survey design and used 246 basic school mathematics teachers. The study revealed that, both categories of mathematics teachers operate at the same level in terms of School Algebra knowledge and Advanced Algebra knowledge. However, professional basic school mathematics teachers' higher teaching knowledge contributed significantly in placing them ahead of the non-professionals in the overall algebra teaching knowledge. It finally showed that, the algebra teaching knowledge of both categories of mathematics teachers do not improve as their years of teaching experience increase. We recommended that stakeholders (Ministry of Education and Ghana Education Service) should organise in-service training for non-professional basic school mathematics teachers to help them improve on their teaching knowledge to positively influence their overall algebra teaching knowledge. Finally, it was recommended to stakeholders to make teamwork and regular in-service training an important aspect of teachers' experience since they help in improving teachers' competence on the field.
\end{abstract}

Index Terms- Algebra teaching knowledge, Basic school mathematics teachers, Knowledge of Algebra for Teaching (KAT), Professional and non-professional, Years of teaching experience.

\section{INTRODUCTION}

Igebra functions as a gatekeeper and bedrock for later mathematics courses (Ferrini-Mundy, McCrory, Senk \& Marcus, 2005). A The role of algebra in mathematics is significant that, it is almost impossible for pupils to perform well in mathematics with weak foundation in algebra. This is due to the fact that algebra has applications in almost all the other areas of mathematics (Wilmot, Yarkwah \& Abreh, 2018). This implies that basic school pupils need strong foundation in algebra to positively influence their general performance in mathematics, since mathematics falls largely on algebra.

Teachers' good repertoire of knowledge in algebra has a positive relationship and effect on pupils' achievement in mathematics (Eisenberg, 1977; Wilmot, 2009; Yarkwah, 2017). This is due to the fact that, it is out of the knowledge teachers possess that they teach and almost impossible for teachers to effectively impart knowledge they do not possess to pupils. In view of this, the algebra teaching knowledge level of basic school mathematics teachers should be monitored to positively affect students' algebra knowledge, hence their general performance in mathematics at the basic school level.

Over the years, basic school pupils in Ghana have demonstrated weak control over algebra related questions in the Basic Education Certificate Examinations (BECE). This has contributed significantly to the poor performance of pupils in the examinations for about a decade now and confirms the assertion that, students' performance in algebra is particularly worrisome (Blume, 2000; RAND Mathematics Study Panel, 2003) and affects their general performance in mathematics (Willmot et al., 2018). For example, the chief examiners' reports for mathematics in the Basic Education Certificate Examination (2011, 2012, 2013, 2014, 2015,2017 \& 2018) highlighted on the following issues regarding pupils' performance on algebra related items.

Basic school pupils have difficulty in:

1. working with variables, especially where variables are more than one.

2. removing brackets, especially brackets within brackets and brackets with exponents.

3. solving problems involving fractions

4. applying BODMAS correctly

5. simplifying and handling Algebraic Expressions 
In looking out for possible reasons for basic school pupils' inability to demonstrate adequate control over algebra related items in the Basic Education Certificate Examinations (BECE), it is very important to investigate if basic school mathematics teachers have the knowledge it takes to teach algebra and algebra related contents effectively at the basic school level. This is because the algebra teaching knowledge of mathematics teachers affect pupils' general performance in mathematics (Wilmot et al., 2018; Yarkwah, 2017). Although many factors affect a teacher's effectiveness, teacher knowledge (subject matter knowledge, in this case, algebra content knowledge) is one of the key factors that influence classroom atmosphere and student achievement (Fennema \& Franke, 1992). Research also shows that students perform well when assigned effective teachers in terms of content knowledge (Ogar, 2006). Agreeing to Ball, Hill, and Bass (2005), the quality of mathematics teaching depends on teachers' mathematical content knowledge; and, alarmingly, many teachers lack firm mathematical understanding and skill. If teachers have strong foundation in subject matter and pedagogy, it will affect pupils positively in their performance in mathematics and help in building strong foundations for their future. Ball, Thames and Phelps (2008) have made it clear that, there may be nothing more foundational to teacher competency than how well teachers know the subjects they teach: algebra is no exception.

\section{LITERATURE REVIEW}

\section{Conceptual Framework}

An in-depth analysis of literature and the work of the researchers in the Knowledge of Algebra for Teaching (KAT) Project theorized that, the comprehensive Knowledge for teaching Algebra is made up of three types of knowledge (Ferrini-Mundy, Senk, \& McCrory, 2005). These include,

1. Knowledge of School Algebra

2. Advanced Algebra Knowledge

3. Algebra Teaching Knowledge

Researchers of the Knowledge of Algebra for Teaching (KAT) have also revealed that, the three types of knowledge for the teaching algebra as stated above are not hierarchical and do not exist in continuum with well-defined borders. Instead, their borders are blurry and intertwined in numerous ways (Ferrini-Mundy et al., 2005). It is also important to note that, the combination of the three knowledge types produce an ultimate knowledge of higher degree (Pedagogical Content Knowledge in Algebra) which enhances teachers' ability to properly communicate algebra contents to pupils to influence their performance in mathematics.

Figure 1 is a diagrammatic representation of the relationship between the three knowledge types and the higher knowledge produced from their integration.

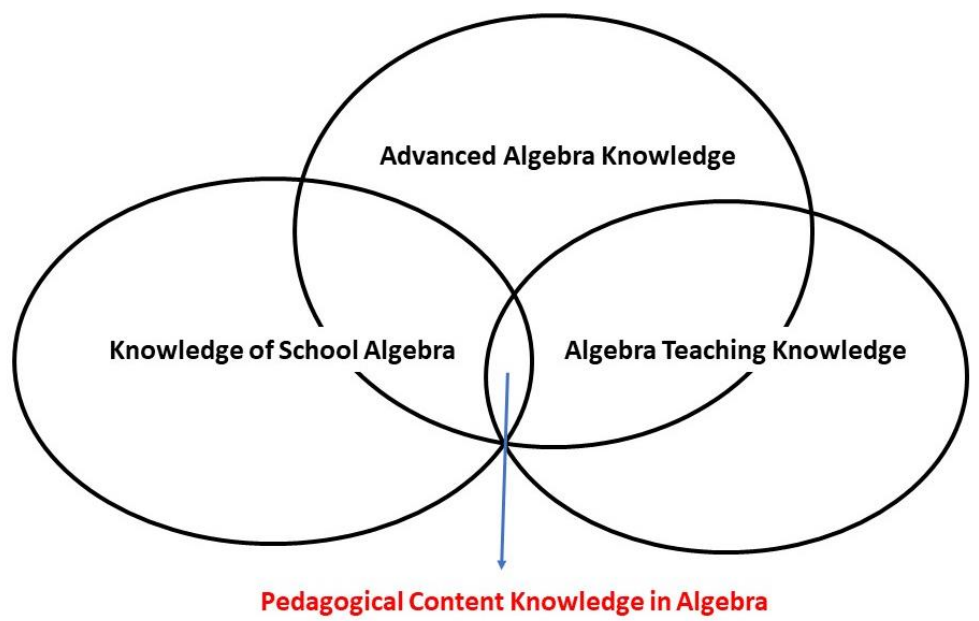

Figure 1: Conceptual Representation of the types of Algebra Knowledge (Ferrini- Mundy et al., 2005; Willmot et al., 2018)

\section{Knowledge of School Algebra}

Knowledge of School Algebra refers to the content of school algebra that mathematics teachers are expected to help students discover or learn in their algebra class, they are found within the intended curriculum (Wilmot, 2008). It sounds realistic, however, to conjecture that for teachers to impact students learning, the teachers themselves need to understand the content of school algebra since pupils are expected to learn such (Wilmot et al., 2018; Yarkwah, 2017). This content is what is mostly found in textbooks and other resources for teaching basic school mathematics. Teachers' ability to demonstrate control over these contents will significantly affect Junior High School pupils' knowledge in the area of algebra and subsequently their general mathematics performance (Wilmot, 2019) 


\section{Advanced Algebra Knowledge}

The Advanced Knowledge of Mathematics is defined in the Knowledge of Algebra for Teaching (KAT) Project as other knowledge which gives a teacher perspective trajectory and growth of mathematical ideas beyond school algebra (Ferrini-Mundy $e t$ al., 2005). Areas that incorporate the Advanced Algebra Knowledge of Mathematics include; sets of numbers, operations on numbers and Algebraic Expressions etc. (Wilmot, 2019). Again, knowing alternate definitions, extensions and generalizations of familiar theorems, and a wide diversity of the uses of school mathematics are also features of an advanced standpoint of mathematics (FerriniMundy et al., 2005). This type of knowledge is also referred to as the applied algebra. It is the Application of the algebra contents in other topics. Hence, it can be maintained that having an advanced viewpoint of mathematics gives teachers a deeper understanding of algebra. The relevance of this type of algebra knowledge is clear because, it makes it possible for a teacher to make appropriate networks across topics, eliminating difficulties while retaining integrity and unzipping of content of school algebra to learners whereas unloading the complexity of mathematics content to make that content more understandable (Yarkwah, 2017). Moreover, it is hoped that any basic school mathematics teacher who possess this type of knowledge would hold quite a respectable knowledge of the path of the content of school mathematics.

\section{Algebra Teaching Knowledge}

Teaching Knowledge is the knowledge that is precise to the teaching of algebra that may not be taught in advanced mathematics courses (Ferrini-Mundy et al., 2005). It comprises such things as what makes a particular concept problematic to learn and what misconceptions lead to precise mathematical inaccuracies. It also contains mathematics required to identify mathematical goals, within and across lessons, to choose among algebraic tasks or texts, to select what to highlight with curricular paths in mind and to ratify other tasks of teaching. Also, this type of algebra knowledge deals with how the content knowledge of algebra is communicated to basic school pupils and may look at how mathematics teachers impart the algebraic knowledge they possess to basic school pupils in the mathematics classroom. Furthermore, this is the type of knowledge teachers possess and apply in teaching the subject matter of school algebra (Yarkwah, 2017). Again, the KAT Project mentioned that, the teaching knowledge of algebra may fall into the kind of pedagogical content knowledge or purely mathematical content applied to teaching (Ferri-Mundy et al., 2005). This type of knowledge distinguishes a Mathematics Educator (Algebra teacher) from a Mathematician or an Engineer (Yarkwah, 2017).

\section{Pedagogical Content Knowledge in Algebra}

Pedagogical Content Knowledge in Algebra comes into play when the three types of Algebra knowledge (Knowledge of School Algebra, Advanced Algebra Knowledge and Algebra Teaching Knowledge) as conceptualized by Ferri-Mundy et al. (2005) intersect. It ensures effective communication of algebra contents to pupils in the mathematics classroom. This is due to the fact that; it brings to play the three types of algebra knowledge required to communicate algebra effectively to pupils. Basic school mathematics teachers who possess this type of advanced knowledge can contribute greatly to pupils' performance in algebra which will influence their general mathematics performance. This type of Pedagogical knowledge is domain specific with respect to algebra.

\section{Years of teaching experience and teachers' algebra knowledge}

Basic school mathematics teachers' knowledge of algebra for teaching is expected to improve as their years of teaching experience increase, this is because teachers learn through their teaching experiences (Klecker, 2002; Rosenholtz, 1986). Leikin, (2006) said it best in our view, the main source of teachers' expertise is their interactions with students and learning materials. Again, one of the indicative variables for teacher competence is teachers' years of teaching experience (Darling-Harmmond, 2000). Research has established that, teachers with more years of teaching experience are more effective than inexperienced teachers; especially those with less than three years of teaching experience (Klecker, 2002; Rosenholtz, 1986). It is therefore expected that basic school mathematics teachers who have spent more years on the field demonstrate higher knowledge in algebra as compared to those who have spent few years on the field as in-service mathematics teachers.

Also, teaching experience has a positive and significant effect on students' achievement. For instance, Jones (1997) claimed that students tend to achieve better results when taught by teachers with more years of teaching experience. Bodenhausen (1988) and Klecker (2002) found teaching experience as one of the determinants of students' achievement and highlighted on the role of improved teachers' knowledge as their years of teaching experience increase. For example, in Klecker's study, there was an examination of the relationship between teachers' years of teaching experience and students' mathematics achievement. The research took into consideration students' scores on eighth grade National Assessment of Education progress (NAEP) mathematics test and the teaching experience of mathematics teachers measured on five categories: 2 years and below, 3-5 years, 6-10 years, 11-24years and $25 y e a r s$ and above. The result showed that, students of teachers with higher teaching experience performed well as compared to students with teachers of low teaching experiences (Klecker, 2002).

\section{METHODS}

\section{Research design}

The study employed the descriptive survey design as it aimed at exploring the algebra teaching knowledge of basic school mathematics teachers through a process of data collection that helps the researchers to describe the situation comprehensively than will be possible without using this method (Fox \& Bayat, 2007). The study examined the algebra teaching knowledge of basic school 
mathematics teachers based on the three basic knowledge types and the ultimate knowledge produced when these knowledge types are combined as theorised in the Knowledge of Algebra for Teaching (KAT) Framework. The research adapted a teacher made achievement test instrument from the Knowledge of Algebra for Teaching (KAT) Project, Black (2008) and Yarkwah (2017) for data collection. The researchers adjusted the above listed instruments in subject matter and pedagogy to fit the basic school level. The teacher-made achievement test was made up of thirty-five (35) items on knowledge of algebra for teaching at the basic school level. The instrument had twelve (12) items on School Algebra Knowledge, fourteen (14) items on Advanced Algebra Knowledge and nine (9) items on Algebra Teaching Knowledge. The instrument was pilot tested and yielded a test re-test reliability of 0.71 on 56 basic school mathematics teachers. This reliability is acceptable based on Nunnally and Bernstein (1994) and Vaske's (2008) recommendation that reliability coefficients within the range of $0.65-0.80$ are 'adequate' and acceptable. On this basis, the instrument was considered suitable for data collection for the main study.

\section{Selection of participants}

The target population for this study was basic school mathematics teachers in Ghana. Basic schools were conveniently sampled and simple random sampling technique was employed in selecting 246 out of 303 basic school mathematics teachers using computer-generated random numbers as sample for the study (Krejcie \& Morgan, 1970).

\section{Procedure}

The researchers initially introduced themselves to the participants. The participants were told that the study was meant to gather information about their knowledge for teaching algebra at the basic school level. They were assured of anonymity of their responses and this was further emphasised in print on the teacher made achievement test. The instrument used for the study was administered to respondents in their respective basic schools within two months. An initial introduction was done and permission was sought from headmasters of the various basic schools involved. The researchers then met respondents in their respective schools and explained to them the purpose of the study, the duration involved in answering the items of the instrument, the measures to ensure privacy of the data collected from participants and the potential benefits of partaking in the study for their consent to participate in the study. There were few basic school mathematics teachers who decided not to partake in the study and they were allowed to opt out. Some respondents agreed to answer the teacher-made achievement test right after our meeting with them, others also scheduled different times for the administration of the test.

\section{Data analysis}

The research hypotheses were answered using the achievement test scores of respondents. The study used descriptive statistics such as means and standard deviations. It also employed independent samples t-test and Analysis of Variance (ANOVA) in providing answers to the various objectives of the study. Results were presented using tables and charts for meaningful and easy interpretations.

\section{RESULTS AND DISCUSSIONS}

\section{Preliminary Analysis}

Data collected on the professional qualifications of the basic school mathematics teachers were also analysed. Table 1 presents the distribution of teachers into professional and non-professional basic school mathematics teachers.

Table 1: Distribution of teachers based on professional qualification

\begin{tabular}{|l|c|c|}
\hline & Frequency & Percentage \\
\hline Professional & 169 & 68.7 \\
\hline Non-professional & 77 & 31.3 \\
\hline Total & 246 & 100 \\
\hline
\end{tabular}

Analysis of the background data revealed that majority of the participants, that is $169(68.7 \%)$ had received professional training from recognised teacher training institutions, making them professional basic school mathematics teachers whiles 77 (31.3\%) of the participants had not received any form of professional training for teaching mathematics at the basic school level (Nonprofessionals), however, these non-professionals teachers were teaching mathematics at the basic school level with either Senior High School certificates or any other equivalent certificate.

\section{$H_{01}$ : There is no statistically significant difference across the algebra knowledge types of professional and non-professional basic school mathematics teachers.}

The first research hypothesis sought to find out if there is a significant difference across the algebra knowledge types of professional and non-professional basic school mathematics teachers. To answer this research hypothesis, the achievement test scores 
of professional and non-professional basic school mathematics teachers across the knowledge types (Knowledge of School Algebra, Advanced Algebra knowledge and Algebra Teaching knowledge) were used. An independent samples t-test was employed in comparing the mean scores obtained on each algebra knowledge type by professional and non-professional basic school mathematics teachers. The analysis was done at 5\% level of significance. The descriptive statistics and independent samples t-tests on the various knowledge types for the two categories of basic school mathematics teachers are displayed in Table 2.

Table 2: Descriptive Statistics and Independent samples t-test results across the algebra knowledge types for professional and non-professional basic school mathematics teachers

\begin{tabular}{|c|c|c|c|c|c|}
\hline Type of Algebra Knowledge & Qualification & Mean & Std. Deviation & $\mathbf{t}$ & p-value \\
\hline \multirow{2}{*}{ School knowledge } & Professional & 15.72 & 5.341 & \multirow{2}{*}{0.411} & \multirow{2}{*}{0.682} \\
\hline & Non-Professional & 15.42 & 5.609 & & \\
\hline \multirow[t]{2}{*}{ Advanced Knowledge } & Professional & 16.67 & 5.735 & \multirow[t]{2}{*}{1.494} & \multirow[t]{2}{*}{0.137} \\
\hline & Non-Professional & 15.45 & 6.284 & & \\
\hline \multirow[t]{2}{*}{ Teaching Knowledge } & Professional & 15.17 & 5.493 & \multirow[t]{2}{*}{3.997} & \multirow[t]{2}{*}{$0.000 *$} \\
\hline & Non-Professional & 12.62 & 4.171 & & \\
\hline \multirow[t]{2}{*}{ Overall Knowledge } & Professional & 47.56 & 10.482 & \multirow[t]{2}{*}{2.981} & \multirow[t]{2}{*}{$0.003 *$} \\
\hline & Non-Professional & 43.49 & 8.514 & & \\
\hline
\end{tabular}

The results in Table 2 show the performance of professional and non-professional basic school mathematics teachers on the various knowledge types for teaching algebra at the basic school level. It can be observed that, professional basic school mathematics teachers recorded relatively higher mean scores in all the knowledge types and also in the overall knowledge for teaching algebra with relatively smaller standard deviations except in teaching knowledge $(\mathrm{SD}=5.493)$ and overall algebra knowledge $(\mathrm{SD}=10.482)$ highlighting on how spread their scores were as compared to non-professional mathematics teachers at these levels.

An independent samples t-test was conducted to ascertain whether there is a significant difference between the algebra knowledge of professional and non-professional basic school mathematics teachers in each knowledge type. Looking at School Knowledge, a p-value of 0.682 compared to an alpha value of 0.05 indicate that there is no statistically significant difference between the school algebra knowledge of professional and non-professional basic school mathematics teachers. Also, the t-test on the advanced algebra knowledge yielded a p-value of $0.137>\alpha=0.05$, showing no significant difference between the advanced algebra knowledge of professional and non-professional basic school mathematics teachers. Again, the t-test comparing the teaching knowledge of professional and non-professional basic school mathematics teachers yielded a p-value of $0.000<\alpha=0.05$, indicating a statistically significant difference in favour of professional basic school mathematics teachers. Finally, the overall algebra teaching knowledge yielded a p-value of $0.003<\alpha=0.05$, showing a significant difference between the overall algebra teaching knowledge of professional and non-professional basic school mathematic teachers in favour of the professionals.

The outcome regarding the observed difference between the teaching knowledge of professionals and non-professionals, which led to a difference in the overall algebra teaching knowledge was not surprising. This is due to the fact that, teaching knowledge, which is the kind of knowledge that is specific to the teaching of algebra and may not be taught in advanced mathematics courses is one of the important issues which gets attention during the training of prospective mathematics teachers (Ferrini-Mundy et al., 2005). It also deals with what makes a particular concept problematic to learn and what misconceptions lead to precise mathematical inaccuracies and distinguishes a trained teacher (professional) from an untrained teacher (non-professional).

\section{$\mathrm{H}_{02}$ : There is no statistically significant improvement in the algebra teaching knowledge of basic school mathematics teachers as their years of teaching experience increase.}

The second research hypothesis sought to find out if there is a significant improvement in the algebra teaching knowledge of basic school mathematics teachers as their years of teaching experience increase. In answering this research objective, the test scores of basic school mathematics teachers were categorized into three major groups based on their years of teaching experience, namely; 5 years and below, $6-10$ years and above 10 years. One way analysis of variance (ANOVA) was employed to check if there is a significant difference in algebra teaching knowledge across the three groups of basic school mathematics teachers based on years of teaching experience. The analysis of variance (ANOVA) was done at 5\% level of significance. Table 3 presents the descriptive statistics of test scores based on years of teaching experience.

Table 3: Descriptive statistics on test scores of basic school mathematics teachers based on years of teaching experience

\begin{tabular}{|l|c|c|c|}
\hline Teaching Experience & N & Mean & Std. Deviation \\
\hline 5 years and below & 107 & 46.15 & 9.757 \\
\hline 6 years -10 years & 98 & 46.07 & 9.884 \\
\hline
\end{tabular}




\begin{tabular}{|l|c|c|c|}
\hline Above 10 years & 41 & 47.15 & 11.442 \\
\hline Total & 246 & & \\
\hline
\end{tabular}

A cursory look at Table 3 reveals a total of 246 basic school mathematics teachers with 107 (43.5\%) having 5 years or less teaching years of experience, 98 (39.8\%) having teaching experience ranging from 6 to 10 years and 41 (16.7\%) having more than 10 years teaching experience. It can also be observed that, basic school mathematics teachers who had more than 10 years of teaching experience obtained the highest mean score and standard deviation $(\mathrm{M}=47.15, \mathrm{SD}=11.442)$. The mean scores and standard deviations obtained by those with 5 years and below and $6-10$ years teaching experience are $(M=46.15, S D=9.757)$ and $(M=$ 46.07, $\mathrm{SD}=9.884$ ) respectively.

Moreover, a pictorial view of the changes in the algebra teaching knowledge of basic school mathematics teachers as their years of teaching experience increase was necessary to display clearly the changes in algebra knowledge as years of teaching experience increase. Below is a diagrammatic representation of the changes in mean scores for the three categories of basic school mathematics teachers.

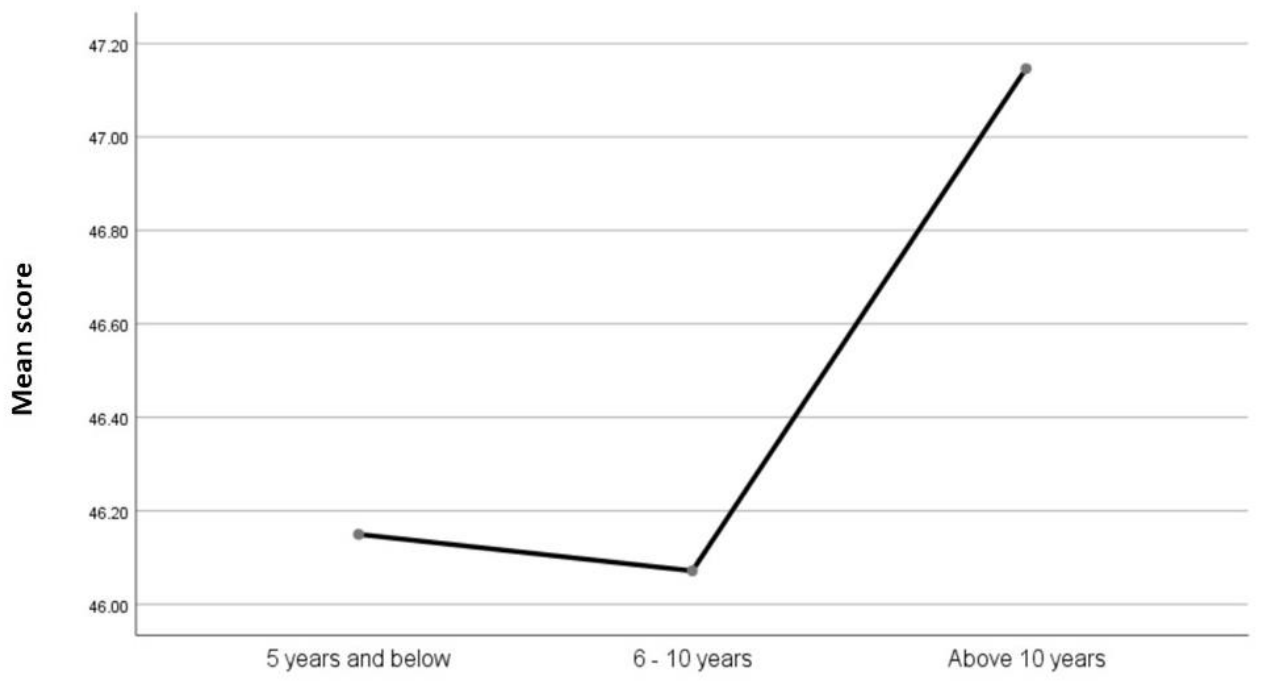

Years of teaching experience

Figure 2: Mean score plot for basic school mathematics teachers based on years of teaching experience

Figure 2 is the mean score plot of basic school mathematics teachers based on years of teaching experience. It can be observed that, the mean score of mathematics teachers with 5 years or less teaching experience is relatively higher than that of those with $6-10$ years showing a decrease in algebra knowledge from 5 years and below to $6-10$ years of teaching experience. It is however the opposite since the algebra teaching of mathematics teachers with above 10 years teaching experience recorded a relatively higher mean score indicating and increase in algebra knowledge. Nevertheless, a one-way analysis of variance (ANOVA) was employed to ascertain whether the changes observed in the mean scores were significant or not.

The output of the one-way analysis of variance (ANOVA) on the test scores of basic school mathematics teachers is presented in Table 4.

Table 4: ANOVA test results for the three categories of basic school mathematics teachers based on years of teaching experience

\begin{tabular}{|l|c|c|c|c|c|}
\hline & Sum of Squares & Df & Mean Square & F & Sig. \\
\hline Between Groups & 36.852 & 2 & 18.426 & .181 & .835 \\
\hline Within Groups & 24805.229 & 243 & 102.079 & & \\
\hline Total & 24842.081 & 245 & & & \\
\hline
\end{tabular}

Table 4 displays the output of the one-way analysis of variance (ANOVA) on the test scores of basic school mathematics teachers based on years of teaching experience. A significant value of 0.835 , which is greater than $\alpha$ value of 0.05 implies that, there is no significant difference across the three categories of basic school mathematics teachers based on years of teaching experience. This 
implies that, basic school mathematics teachers with 5 years and below, 6 - 10 years and above 10 years teaching experience have relatively the same algebra teaching knowledge, indicating that their algebra teaching knowledge do not improve significantly as their years of teaching experience increase.

This finding is in contradiction to the claim that, one of the indicative variables for teacher competence is teachers' years of teaching experience and that, teachers with more years of teaching experience are more effective than inexperienced teachers; especially those with less than three years of teaching experience (Klecker, 2002; Rosenholtz, 1986; Darling-Harmmond, 2000). It however, sits with the findings of Osei (2020) where mathematics teachers with more than 10 years and those with $6-10$ years of teaching experience demonstrated the same level of knowledge as those with 5 years and below teaching experience as in-service mathematics teachers.

\section{CONCLUSIONS AND RECOMMENDATIONS}

Based on the findings of the study, we conclude that professional and non-professional basic school mathematics teachers have relatively the same level of knowledge in terms of School Algebra Knowledge and Advanced Algebra Knowledge. However, professional basic school mathematics teachers possess higher knowledge in Teaching Knowledge (related to pedagogy) and the overall Algebra Teaching Knowledge as compared to non-professional basic school mathematics teachers. We therefore recommended that, stakeholders of basic school education in Ghana (Ministry of Education and Ghana Education Service) organise in-service training on teaching knowledge for non-professional basic school mathematics teachers to help them improve on their pedagogical issues to positively affect their overall algebra teaching knowledge.

Also, it can be concluded that, the algebra teaching knowledge of basic school mathematics teachers do not improve significantly as their years of teaching experience increase. Basic school mathematics teachers who have spent more years on the field as in-service teachers have the same level of algebra teaching knowledge as those with few years of teaching experience. It therefore recommended that, teamwork and regular in-service training which are helpful ways of improving teacher competence be made an important part of basic school teachers' experience on the field.

\section{REFERENCES}

[1] Ball, D. L., Hill, H. C., \& Bass, H. (2005). Knowing mathematics for teaching: Who knows mathematics well enough to teach third grade and how can we decide? American Educator, Fall, 14-46.

[2] Ball, D. L., Thames, M. H., \& Phelps, G. (2008). Content knowledge for teaching: What makes it special. Journal of Teacher Education, (59), $389-407$.

[3] Black, D. J. B. (2008). The relationship of teachers' content knowledge and pedagogical content knowledge in algebra and changes in both types of knowledge as a result of professional development. Unpublished Ph. D Thesis, Aubum, Alabama

[4] Blume, G. W., \& Heckman, D. S. (2000). 'Algebra and functions'. In E. A. Silver \& P. A. Kenney (Eds.), Results from the seventh mathematics assessment of the National Assessment of Educational Progress (pp. 269-306). Reston, VA: National Council of Teachers of Mathematics.

[5] Bodenhausen, J. (1988). Does the academic background of teachers affect the performance of their students? Paper presented at the Annual Meeting of the American Educational Research Association, New Orleans, LA. (ERIC Document Reproduction No. ED293836)

[6] Darling-Hammond, L. (2000). Teacher quality and students' achievement: A review of state policy evidence. Working paper, Center for the study of teaching and policy, University of Washington.

[7] Eisenberg, T. A. (1977). Begle revisited: Teacher knowledge and student achievement in algebra. Journal for research in mathematics Education, 8(30), $216-222$.

[8] Fennema, E. \& Franke, M. (1992). Teachers' knowledge and its impact in: D.A. Grouws(Ed) Handbook of Research on Mathematics Teaching and Learning (New York: Macmillan Publishing)

[9] Ferrini-Mundy, J., McCrory, R., Senk, S. L., \& Marcus, R (2005). Knowledge for algebra teaching. A paper presented to the American Educational Research Association (AERA) Annual Meeting in Montreal, Canada, on April 14, 2005.

[10] Ferrini-Mundy, J., Senk, S. \& McCrory, R. (2005). Measuring secondary school mathematics teachers' knowledge of mathematics for teaching: Issues of conceptualization and design. Paper presented to the ICMI study conference in Aguas de Lindoia, Brazil in May 2005.

[11] Fox, W., \& Bayat, M. S. (2007). A Guide to Managing Research. Juta Publications.

[12] Klecker, B. M. (2002). The Relationship between Teachers' Years of Teaching Experience and Students' Mathematical Achievement. Paper presented at the Annual Meeting of the Mid-South Educational Research Association, Chattanooga, TN.

[13] Krejcie, R. V., \& Morgan, D. W. (1970). Determining sample size for research activities. Educational and Psychological Measurement, $30,607-610$.

[14] Nunnally, J. C., \& Bernstein, I. H. (1994). Psychometric theory (3). New York: McGraw-Hill.

[15] Ogar, M. N. (2006). Instructional Media, Learner, Teacher and Classroom Factors as Correlates of secondary school students learning outcomes in English language. Unpublished Ph. D Thesis, University of Ibadan, Ibadan, Nigeria.

[16] Osei, W. (2020) Algebra teaching knowledge of basic school mathematics teachers. An Unpublished masters thesis submitted, Department of Mathematics and I.C.T. Education, University of Cape Coast.

[17] RAND Mathematics Study Panel, \& Ball, D. L., Chair: 2003, Mathematical Proficiency for All Students. Santa Monica CA: RAND.

[18] Rosenholtz, S. J. (1986). The organizational context of teaching: In Learning to Teach. Champaign-Urbana: University of Illinois. 
[19] Vaske, J. J. (2008). Survey research and analysis: Applications in parks, recreation and human dimensions. State College, PA: Venture.

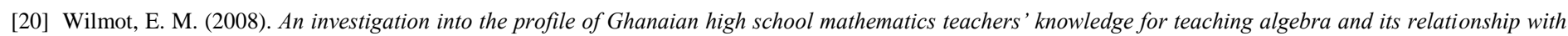
students' performance. Unpublished doctoral thesis submitted to Michigan State University.

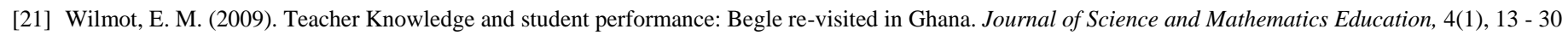

[22] Wilmot, E. M. (2019). Re-conceptualising teacher knowledge in domain specific terms. Ghana journal of Education: Issues and practice (GJE).

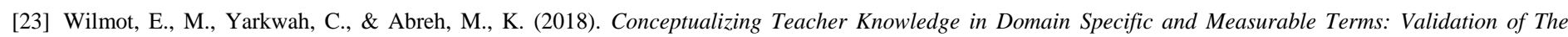
Expanded Kat Framework. British Journal of Education Vol.6, No.7, pp.31-48, July 2018

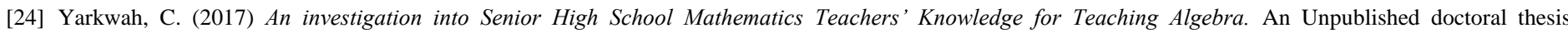
submitted, Department of Mathematics and I.C.T. Education, University of Cape Coast.

\section{AUTHORS}

First Author - Williams Osei, MPhil. Mathematics Education, University of Cape Coast, Department of Mathematics and ICT Education, Ghana, williams.osei@stu.edu.gh

Second Author - Maud Kabukie Kubi, Bachelor of Education, Basic Education, University of Education, Winneba, Department of Basic Education, Ghana, maudkubi@gmail.com

Correspondence Author - Williams Osei, williams.osei@stu.edu.gh, wills.osei2020@gmail.com, contact number. +233 545322678 